\title{
Low-Molecular-Weight Heparins, Acenocoumarol and Bone Density
}

\author{
L. Wawrzyńska ${ }^{a} \quad$ J. Przedlacki ${ }^{b} \quad$ B. Hajduk ${ }^{a}$ \\ H. Bielska Faldac W. Tomkowski a Aorbicki ${ }^{a}$ \\ aDepartment of Internal Chest Medicine, Institute of Tuberculosis and Lung Diseases, \\ ${ }^{b}$ Department of Internal Medicine and Nephrology, Medical University, \\ ${ }^{c} 1$ st Department of Surgery, Medical University, Warsaw, Poland
}

\section{Dear Sir,}

Recently, we published the results of a Polish multicentre trial which showed the efficacy of low-molecular-weight heparin (LMWH) when compared to acenocoumarol for secondary prophylaxis of VTE episodes [1]. However, a growing number of patients without reversible risk factors for VTE are assigned to periods of secondary prophylaxis extending beyond 6 months, because of a perceived high risk of late recurrence. Whether LMWH can be considered in this clinical context as an alternative to oral anticoagulants requires an update of our understanding of the adverse effects of this group of anticoagulants when administered over longer periods of time. We would like to share our initial experience regarding the risk of osteoporosis during secondary prophylaxis with LMWH in patients after VTE.
Osteoporosis is a well-recognized complication of prolonged treatment with unfractionated heparin [2-4]. Generally, the intensity of bone structure disturbance is believed to depend on the total administered dose of unfractionated heparin. However, only a few published reports have directly addressed this problem since 1965 . Only isolated publications report on the influence of UFH, LMWH and oral anticoagulants on bone structure $[5,6]$.

Our experience consists of a prospective observation of 54 patients (26 females, 28 males, age 22-75 years, average 56.7 years) assigned to secondary prophylaxis after episodes of VTE. Nadroparine $(15,000 \mathrm{IU} /$ day s.c.) was used in 15 patients, enoxaparine $(1 \mathrm{mg} / \mathrm{kg} /$ day s.c.) in 15 patients and acenocoumarol (administered to reach a target range of INR 2.0-3.0) in 24 patients.
Each patient was evaluated for bone structure abnormalities twice: firstly after 10-14 days of initial treatment for VTE and then after either 3 months of secondary prophylaxis in those patients who received nadroparine or acenocoumarol or after 6-12 months in those receiving enoxaparine. Bone structure was assessed by densitometry (according to the DEXA method with LUNAR DPX-L, Lunar, Madison, Wisc., USA). Two different bones (femur and lumbar spine 2-4) were studied. The initial bone mineral density (BMD) as measured by densitometry was assigned a value of $100 \%$ and compared to the final BMD result, expressed as the percentage difference from the initial value. In addition, the $\mathrm{Z}$ score was assessed, defined for individual patients as the number of standard deviations from an ideal BMD value for age and sex subgroups.

\begin{tabular}{ll}
\hline KARGER & ○ 2001 S. Karger AG, Basel \\
$\begin{array}{l}\text { Fax + 41 61306 1234-0147/01/0311-0069\$17.50/0 } \\
\begin{array}{l}\text { E-Mail karger@karger.ch } \\
\text { www.karger.com }\end{array}\end{array}$ & $\begin{array}{l}\text { Accessible online at: } \\
\text { www.karger.com/journals/hae }\end{array}$
\end{tabular}

\author{
Liliana Wawrzyńska \\ Department of Internal Chest Medicine \\ Institute of Tuberculosis and Lung Diseases \\ PL-01-138 Warsaw, Plocka 26 (Poland) \\ Fax +48 22691 2414, E-Mail I.wawrzynska@igichp.edu.pl
}


Table 1. Changes in BMD values and $\mathrm{Z}$ scores

\begin{tabular}{|c|c|c|c|c|c|c|}
\hline \multirow[t]{3}{*}{ Treatment } & \multirow[t]{3}{*}{ Patients } & \multirow{3}{*}{$\begin{array}{l}\text { Time } \\
\text { months }\end{array}$} & \multicolumn{4}{|c|}{ Changes in bone mineral content } \\
\hline & & & \multicolumn{2}{|l|}{ femur } & \multicolumn{2}{|c|}{ lumbar spine } \\
\hline & & & $\Delta \mathrm{BMD}, \%$ & DZ score & $\Delta \mathrm{BMD}, \%$ & $\Delta \mathrm{Z}$ score \\
\hline Nadroparine & 15 & 3 & -1.35 & -0.07 & -1.2 & -0.13 \\
\hline Enoxaparine & 15 & $6-12$ & -2.94 & -0.1 & -3.6 & -0.15 \\
\hline Acenocoumarol & 13 & 3 & +0.08 & -0.04 & -1.24 & -0.15 \\
\hline Acenocoumarol & 11 & $6-12$ & -2.71 & -0.29 & -1.71 & -0.28 \\
\hline
\end{tabular}

In all four subgroups of patients, decreased bone density was evidenced, both as a decrease in BMD and more negative $\mathrm{Z}$ score values. This trend was least marked in patients after 3 months of acenocoumarol (BMD lumbar spine $-1.24 \%$, BMD femur increased by $+0.08 \%)$, more marked in patients after 3 months of nadroparine (BMD lumbar spine $-1.2 \%$, BMD femur $-1.35 \%$ ) and most evident after 6-12 months of enoxaparine (BMD lumbar spine $-3.6 \%$, BMD femur $-2.94 \%$ ).

Similarly, the Z score also decreased (table 1). A statistically significant value was determined only between the subgroups of patients receiving enoxaparine and for patients after 3 months of acenocoumarol: $\mathrm{p}<0.05$.

Our observations are similar to those published earlier by Monreal et al. [7]. They suggest a consistent, though modest decrease in BMD during pharmacological secondary prophylaxis of VTE. It should be remembered that the natural decrease in BMD is estimated at $1 \%$ per year. It is difficult to determine whether differences in the intensity of observed changes were due to intrinsic differences in the two LMWH treatments which were used or rather to the different dura- tion of treatment, with the latter being more probable. Interestingly, slight deterioration of bone structure was also found in patients on acenocoumarol treatment [7]. This change in bone mineral content in patients receiving acenocoumarol was in fact of a similar level when compared to patients receiving LMWH over the same period of time.

Whether changes in bone density in patients on secondary prophylaxis with acenocoumarol are due to the intrinsic effect of coumadin derivatives or rather to concomitant risk factors for osteoporosis, such as age, sedentary lifestyle and diet, cannot be assessed from our data. However, regardless of the cause, it seems that prolonged secondary prophylaxis with LMWH does not affect bone density more than when acenocoumarol is used for this purpose. Whether and which patients receiving long-term secondary prophylaxis for VTE also require prophylaxis for osteoporosis requires further studies.

\section{References}

1 Łopaciuk S, Bielska-Falda $\mathrm{H}$, Noszczyk W, Bielawiec M, Witkiewicz W, Filipecki S, Michalak J, Ciesielski L, Mackiewicz Z, Częstochowska E, Zawilska K, Cencora A: Low molecular weight heparin versus acenocoumarol in the secondary prophylaxis of deep vein thrombosis. Thromb Haemost 1999;81:2631.

2 Avioli LV: Heparin-induced osteopenia: An appraisal. Adv Exp Med Biol 1975;52:375-387.

3 Matzsch T, Berquist D, Hedner V, Nilsson B, Ostergaard P: Effect of enzymatically depolymerized heparin compared with conventional heparin in healthy volunteers. Thromb Haemost 1987;57:97-101.

4 Miller WE, De Wolfe VG: Osteoporosis resulting from heparin therapy. Cleve Clin Q 1966;33:31-35.

5 Ginsberg JS, Kowalchuk G, Hirsh J, Brill-Edwards P, Burrows R, Coates G, Webber C: Heparin effect on bone density. Thromb Haemost 1990;64:286-289.

6 Levine MN, Hirsh J, Salzman EW: Side effects of antithrombotic therapy; in Colman RW, Hirsh J, Marder VJ, Salzman EW (eds): Haemostasis and Thrombosis. Philadelphia, Lippincott, 1994, pp 936-955.

7 Monreal M, Olive A, Lafoz E, Del Rio L: Heparins, coumarin, and bone density (letter). Lancet 1991; 338:706.
70

Haemostasis 2001;31:69-70
Wawrzyńska/Przedlacki/Hajduk/Falda/ Tomkowski/Torbicki 